OPEN ACCESS

Edited by:

Mark Stecker,

Independent Practitioner, Fresno,

United States

Reviewed by:

Tae In Kam,

Johns Hopkins University,

United States

Fereshteh Farajdokht,

Tehran University of Medical

Sciences, Iran

*Correspondence:

Minho Moon

hominmoon@konyang.ac.kr

Doo-Han Yoo

glovia@konyang.ac.kr

tThese authors have contributed equally to this work

Received: 18 March 2021 Accepted: 14 June 2021

Published: 14 July 2021

Citation:

Kim S, Nam Y, Ham M-J, Park C, Moon M and Yoo D-H (2021)

Neurological Mechanisms

of Animal-Assisted Intervention

in Alzheimer's Disease: A Hypothetical

Review.

Front. Aging Neurosci. 13:682308.

doi: 10.3389/fnagi.2021.682308

\section{Neurological Mechanisms of Animal-Assisted Intervention in Alzheimer's Disease: A Hypothetical Review}

\author{
Sujin Kim ${ }^{1,2 \dagger}$, Yunkwon Nam ${ }^{1 \dagger}$, Min-Joo Ham ${ }^{3 \dagger}$, Chisoo Park ${ }^{3}$, Minho Moon ${ }^{1,2 *}$ and \\ Doo-Han Yoo $2,3 *$ \\ ${ }^{1}$ Department of Biochemistry, College of Medicine, Konyang University, Daejeon, South Korea, ${ }^{2}$ Research Institute \\ for Dementia Science, Konyang University, Daejeon, South Korea, ${ }^{3}$ Department of Occupational Therapy, Konyang \\ University, Daejeon, South Korea
}

Alzheimer's disease (AD) is an irreversible neurodegenerative brain disorder with aggregation of amyloid-beta $(A B)$ and tau as the pathological hallmarks. $A D$ is the most common form of dementia and is characterized by a progressive decline of cognition. The failure of pharmacological approaches to treat $A D$ has resulted in an increased focus on non-pharmacological interventions that can mitigate cognitive decline and delay disease progression in patients with $A D$. Animal-assisted intervention (AAI), a non-pharmacological intervention, improves emotional, social, and cognitive dysfunction in patients with neurodegenerative diseases. In particular, AAl is reported to mitigate the effects of cognitive impairment in patients with $A D$. Despite the positive effects of AAl on cognitive dysfunction in patients with $A D$, there have been no studies on how AAl affects AD-related pathologies. This review postulates potential neurological mechanisms of emotional or social interaction through AAI in countering AD-related pathologies, such as $A \beta$ deposition, tau hyperphosphorylation, neuroinflammation, and impaired adult hippocampal neurogenesis $(\mathrm{AHN})$, and proposes insights for future research by organizing accumulated previous evidence.

\footnotetext{
Keywords: dementia, Alzheimer's disease, animal-assisted intervention, amyloid-beta, tau, neuroinflammation, adult hippocampal neurogenesis
}

\section{INTRODUCTION}

Dementia is a chronic and progressive disease characterized by the deterioration of cognitive function (Arvanitakis et al., 2019). The WHO reported that approximately 50 million people worldwide have dementia, with 10 million incident cases every year (World Health Organization [WHO], 2020). The total number of patients with dementia is predicted to reach 82 million in 2030 and 152 million in 2050. Alzheimer's disease (AD) is the most prevalent type of dementia, accounting for $60-70 \%$ of cases. The principal pathological characteristics of $\mathrm{AD}$ are amyloid-beta $(\mathrm{A} \beta)$ plaques aggregated by $\mathrm{A} \beta$ peptides and neurofibrillary tangles produced by hyperphosphorylation of tau proteins (Querfurth and LaFerla, 2010). Deposition of $A \beta$ and tau in early $\mathrm{AD}$ contributes to increased neuroinflammation and neuronal loss (Mandrekar-Colucci and Landreth, 2010; Tai et al., 2015; Terada et al., 2019). In addition, abnormally accumulated 
$\mathrm{A} \beta$ and tau proteins induce dysfunction of neurotransmitter, such as glutamatergic and gamma aminobutyric acid (GABA)ergic transmitters, leading to impairment of adult hippocampal neurogenesis (AHN) (Sun et al., 2009; Moon et al., 2014; Zheng et al., 2020). Numerous drugs have been developed to treat AD, but most drugs have failed to attenuate cognitive decline or have not slowed down the progression of the disease (Anderson et al., 2017; Cummings et al., 2020). Therefore, non-pharmacological interventions are receiving a lot of attention as an alternative treatment that can alleviate cognitive decline and influence a broad range of $\mathrm{AD}$ pathology.

Animal-assisted intervention (AAI), a non-pharmacological method, is a complementary goal-oriented technique that mainly results from human and animal interactions (Laun, 2003; Macauley, 2006; Sockalingam et al., 2008). The purpose of AAI is related to enhancing the emotional, social, and cognitive functions of the human. Interaction with animals provides unique communication, social support, and love-bonding for patients, which can provide a variety of mental and social health benefits to humans (Barker and Wolen, 2008; Straub, 2011). A therapeutic role of animal interactions has been reported in patients with a variety of diseases, especially neurodegenerative diseases (Laun, 2003; Macauley, 2006; Sockalingam et al., 2008; Olsen et al., 2016a,b; Bunketorp-Käll et al., 2017). Many metaanalysis studies reported that AAI has a therapeutic effect on various diseases regardless of age (Hediger et al., 2021). In patients with psychiatric disorders, such as depression, AAI has been shown to alleviate depression symptoms and restore social functions (Souter and Miller, 2007; Virués-Ortega et al., 2012). In addition, AAI relieved trauma memory in post-traumatic stress disorder patients (Germain et al., 2018; Hediger et al., 2021), and it has been reported that AAI relieves pain and improves gross motor function in children with disabilities (Charry-Sánchez et al., 2018; Zhang et al., 2021). In particular, a study has reported that AAI mitigates negative emotions, such as loneliness, anxiety, fear, and sadness in patients with AD (Mossello et al., 2011). In addition, various studies have reported that AAI affects depression, anxiety, quality of life, and cognitive function in patients with dementia (Majic et al., 2013; Kamioka et al., 2014; Olsen et al., 2016a,b). Furthermore, patients with $\mathrm{AD}$ who received $\mathrm{AAI}$ based on the reality orientation therapy protocol had significantly improved Geriatric Depression Scale and Mini-Mental State Examination scores than those who received only reality orientation therapy (Menna et al., 2016; Santaniello et al., 2020). The previous meta-analysis also showed that AAI has an effect on relieving depression in patients with dementia (Park et al., 2020). Another AAI-related meta-analysis study conducted in patients with dementia has reported that AAI may be effective in diminishing behavioral and psychological symptoms of dementia (BPSD), both in the short and long terms (Hu et al., 2018).

Despite the accumulation of evidence that supports the benefits of $\mathrm{AAI}$ on symptoms of $\mathrm{AD}$, which includes improving cognitive impairment, BPSD, and negative emotions (Kanamori et al., 2001; Bono et al., 2015; Menna et al., 2016; Borges de Araujo et al., 2019; Santaniello et al., 2020), the underlying neurological mechanisms of these benefits have not been identified yet. In particular, we speculated that increased emotional or social interaction through AAI plays an important role in relieving symptoms in patients with $\mathrm{AD}$. Thus, in this review, we focus on the increased emotional or social interactions that are increased via AAI, suggesting several possible neurological mechanisms of AAI that influence AD-related pathologies, such as $\mathrm{A} \beta$ deposition, tau hyperphosphorylation, neuroinflammation, and AHN disorders. Moreover, we propose future studies on AAI in AD-related pathologies.

\section{HYPOTHESES OF THE NEUROLOGICAL MECHANISMS UNDERLYING AAI IN AD-RELATED PATHOLOGY}

\section{The Possible Mechanisms of AAl in AD-Related A $\beta$ Deposition and Tau Hyperphosphorylation}

Regardless of any form of interaction, whether human or animal, an interruption in the interaction can negatively impact a patient experiencing loneliness and anxiety caused by a disease (Leigh-Hunt et al., 2017). Surprisingly, A $\beta$ deposition and tau hyperphosphorylation in the brain are promoted and exacerbated by perceived social isolation or loneliness. One study reported that $A \beta$ accumulation was observed in the brains of elderly patients who felt lonely, regardless of their diagnosis of dementia (Donovan et al., 2016). Moreover, several studies reported that amyloid precursor protein (APP)/presenilin 1 (PS1) transgenic mice in social isolation compared with standard housing have significantly increased levels of $A \beta_{42}$ and $\mathrm{A} \beta_{40}$ caused by increasing $\gamma$-secretase activity and decreasing neprilysin expression (Huang et al., 2011, 2015; Hsiao et al., 2012). Similarly, some studies using rat models have reported that social isolation increases the level of glycogen synthase kinase$3 \beta$ (GSK-3 $\beta$ ) and tau hyperphosphorylation but decreases the level of Ser9-phosphorylated GSK-3 $\beta$ (Ren et al., 2015; Gong and Ren, 2016). This evidence suggests that social isolation and perceived loneliness can promote $A \beta$ production and tau hyperphosphorylation in the brains of those with early AD. In addition, stress from social isolation and loneliness can also affect $\mathrm{A} \beta$ accumulation and tau hyperphosphorylation. Stressinduced increases in glucocorticoid levels lead to exacerbation of $A \beta$ and tau pathologies (Green et al., 2006). In particular, patients with $\mathrm{AD}$ and mild cognitive impairment showed significantly increased plasma and cerebrospinal fluid (CSF) cortisol levels than patients with normal cognition and also showed dysregulation of the hypothalamic-pituitary-adrenal axis (Popp et al., 2015; Ouanes and Popp, 2019). Increased levels of glucocorticoids induced by stress in $3 x \mathrm{Tg}$ mice accelerate the development of neurofibrillary tangles by increasing the accumulation of somatodendritic tau and raising the levels of intraneuronal $A \beta$ through increased levels of APP and $\beta$-secretase (Green et al., 2006). Interestingly, short-term interactions between dogs and owners reduced cortisol levels in their owners (Handlin et al., 2011). In addition, participants who directly touched dogs or cats through animal visiting programs 
and had sensory interactions with animals showed decreased cortisol levels compared with other groups that did not interact with animals (Pendry and Vandagriff, 2019); however, as these mechanisms were not confirmed by directly applying AAI to animal models or patients with $\mathrm{AD}$, future studies are required for confirming the direct effect of AAI on $A \beta$ deposition and tau hyperphosphorylation using positron emission tomography in preclinical or patients with prodromal AD.

\section{The Possible Mechanisms of AAI in AD-Related Neuroinflammation}

A variety of stresses, including a decrease in emotional or social interactions, regardless of the type of interaction, have been reported to increase the levels of inflammatory cytokines and the activity of the inflammatory immune system (CoussonsRead et al., 2007; Audet et al., 2014). In brains of patients with $\mathrm{AD}$, the innate immune response induced by various stresses is converted into chronic inflammation, which contributes to neurodegeneration (Heneka et al., 2015). Chronic stress in the $\mathrm{AD}$ brain promotes the proliferation of glial cells and increases secretion of stress-induced cytokines, such as interleukin (IL)$1 \beta$, IL-6, IL-12, IL-18, and tumor necrosis factor-alpha (TNF$\alpha)$, resulting in impaired neurogenesis and synaptic plasticity (Ricci et al., 2012). Neurodegeneration also contributes to neuroinflammation, the development of a vicious cycle between neuroinflammation and neurodegeneration, and the acceleration of progression of $\mathrm{AD}$ and cognitive decline (Kempuraj et al., 2016). In particular, the disconnection of social interaction increases the levels of pro-inflammatory cytokines, such as IL-6 and TNF- $\alpha$, in the anterior insula and dorsal anterior cingulate cortex (Slavich et al., 2010). In addition, stress due to the disconnection of social interaction increases microglia and astrocyte activity in the hippocampus of aged APP/PS1 mice (Huang et al., 2015). Surprisingly, a meta-analysis of the association between social support-social integration and neuroinflammation has shown that inflammatory cytokines were significantly reduced in the social support group (Uchino et al., 2018). In addition, social interaction significantly reduced the activity of IL- $1 \beta$ and TNF- $\alpha$ in a rat model with AD (Ali et al., 2017). These results reveal that increased emotional or social interaction alleviates the neuroinflammatory response. Importantly, AAI remarkably reduced Stress Visual Analog Scale scores in older patients in intensive care units and slightly reduced IL-1 $\beta$ levels in saliva (Branson et al., 2020). Taken together, increased emotional or social interaction through AAI may mitigate AD-related neuroinflammation by reducing stressinduced pro-inflammatory cytokine release and the activity of microglia and astrocytes. Future studies are needed to confirm the direct effects of AAI on AD-related neuroinflammation by detecting cytokine levels in saliva, blood, and CSF in patients with prodromal or mild AD.

\section{The Possible Mechanisms of AAI in AD-Related Neurodegeneration}

Decreased emotional or social interactions robustly contribute to below-normal-range cognitive function and more rapid cognitive impairment in the development of $\mathrm{AD}$ (Wilson et al., 2007). In a study examining the levels of neurotransmitter immunoreactive neurons using immunohistochemistry, social isolation reduced cholinergic neurons of the vertical diagonal bands in wild-type mice (Huang et al., 2011). In addition, an environment with reduced interaction decreased hippocampal volume, synaptophysin expression, and myelin basic protein expression in aged APP/PS1 mice (Huang et al., 2015). The cholinergic neurons of the vertical and horizontal diagonal bands of Broca's area, noradrenergic neurons of the locus coeruleus, and serotonergic neurons of the raphe nucleus were significantly reduced in isolated APP/PS1 mice compared with APP/PS1 standard housing controls (Huang et al., 2011). Surprisingly, according to various animal models and human studies, the opioid system is a major mediator that influences social functions including social bonding (Barr et al., 2008; Copeland et al., 2011; Trezza et al., 2011; Colonnello et al., 2017). Particularly, opioid receptors are associated with the regulation of neurotransmitters, such as glutamate, GABA, acetylcholine, serotonin, and noradrenaline. In addition, a study investigating the levels of NR2A or NR2B, which is involved in the dendritic arbor and neuronal development in opioid receptor systems, reported that the expression of receptors significantly decreased in both healthy and APP/PS1 mice living in an environment with reduced social interaction compared with a standard housing group (Huang et al., 2011). These results suggest that decreased emotional or social interactions may exacerbate neurodegeneration by inducing dysfunction of the opioid system in AD. Another study using functional magnetic resonance imaging (fMRI) showed that rearing pet insects positively affected executive functions through the activity of the right dorsal lateral prefrontal cortex and parietal cortex in elderly women (Park et al., 2019). In addition, the increased interaction through AAI in a study that measured changes in oxygenated and deoxygenated hemoglobin concentrations using near-infrared spectroscopy significantly increased the oxygenated hemoglobin concentration in the prefrontal cortex of mood disorders patients with low prefrontal cortex activity (Aoki et al., 2012). These results suggest that AAI may induce biological and physiological changes in the prefrontal cortex. Furthermore, application of the combination of AAI and cognitive rehabilitation techniques improved executive function, social skills, and mood regulation in patients with acquired brain injury (Stapleton, 2016; Gocheva et al., 2018), and improved cognitive function and depressive status in patients with $\mathrm{AD}$ (Santaniello et al., 2020). This evidence implicates direct effects of increased interaction through AAI on the brain, and that AAI may also improve functional connectivity and activity in the brains of patients with AD. Therefore, increased emotional or social interaction through AAI might contribute to the inhibition of $\mathrm{AD}$-related neurodegeneration by suppressing the loss of various neurotransmitter-releasing neurons and improving synaptic plasticity by mitigating the dysfunction of the opioid system in the brains of patients with AD. However, because there is little evidence about the mechanism of AAI in the brain of patients with $\mathrm{AD}$, future studies are required for confirming the direct effect of AAI on alterations of networks 
and circuits by using fMRI or diffusion tensor imaging in patients with prodromal or mild AD.

\section{The Possible Mechanisms of AAl in AD-Related Impaired AHN}

The subgranular zone (SGZ) of the hippocampal dentate gyrus (DG) exhibits a unique phenomenon of the creation of new neurons and glial cells throughout life in adult mammals.
This phenomenon is called AHN (Ming and Song, 2011). The AHN process is divided into proliferation, differentiation, maturation, and integration. In addition, this process provides an incomparable degree of neuronal plasticity to the entire hippocampal circuitry. Therefore, AHN plays a significant role in network maintenance and structural plasticity in the hippocampus (Mu and Gage, 2011). Interestingly, several brain disorders, such as neurodegenerative diseases and mood disorders, exhibit dysfunction and dysregulation of $\mathrm{AHN}$, and

TABLE 1 | The effects of AAI on healthy individuals and patients with neurodegenerative disease.

\begin{tabular}{|c|c|c|c|c|c|c|}
\hline \multirow[b]{2}{*}{ Functional decline } & \multicolumn{2}{|c|}{ Participants (Experimental/Control) } & \multicolumn{2}{|c|}{ Intervention } & \multirow[t]{2}{*}{ Main results } & \multirow[t]{2}{*}{ References } \\
\hline & Age & Sample size & Type of AAI & $\begin{array}{l}\text { Period/total number } \\
\text { of sessions }\end{array}$ & & \\
\hline \multirow[t]{4}{*}{ Hormone imbalance } & $42 \pm 8 / 53 \pm 10$ & $10 / 10$ & $\begin{array}{l}\text { Short-term interaction } \\
\text { between dogs and their } \\
\text { owners }\end{array}$ & 1 session & Oxytocin levels $\uparrow$ & Handlin et al., 2011 \\
\hline & & & & & Cortisol levels $\downarrow$ & \\
\hline & & & & & Insulin levels $\downarrow$ & \\
\hline & $19.94 \pm 1.66 /-$ & $249 /-$ & $\begin{array}{l}\text { Animal visitation } \\
\text { programs }\end{array}$ & 1 session & Cortisol levels $\downarrow$ & $\begin{array}{l}\text { Pendry and Vandagriff, } \\
2019\end{array}$ \\
\hline \multirow[t]{3}{*}{ Stress } & $39.9 \pm 16.2 /-$ & $9 /-$ & $\begin{array}{l}\text { Animal-assisted } \\
\text { therapy }\end{array}$ & 5 sessions & Stress $\downarrow$ & $\begin{array}{l}\text { González-Ramírez } \\
\text { et al., } 2013\end{array}$ \\
\hline & $18-25 /-$ & $68 /-$ & $\begin{array}{l}\text { Animal-assisted } \\
\text { programs }\end{array}$ & - & Stress $\downarrow$ & $\begin{array}{l}\text { Haggerty and Mueller, } \\
2017\end{array}$ \\
\hline & $60-86$ & $20 / 20$ & Animal-assisted activity & 20 sessions & Stress $\downarrow$ & Branson et al., 2020 \\
\hline \multirow[t]{5}{*}{ Cognitive dysfunction } & $75.25 \pm 6.06 / 75.1 \pm 5.83$ & $16 / 7$ & $\begin{array}{l}\text { Animal-assisted } \\
\text { therapy }\end{array}$ & 6 months/24 sessions & MMSE $\uparrow$ & Menna et al., 2016 \\
\hline & $76.6 \pm 5.0 / 75.0 \pm 6.3$ & $65 / 31$ & $\begin{array}{l}\text { Animal-assisted } \\
\text { therapy }\end{array}$ & 6 months/24 sessions & MMSE $\uparrow$ & Santaniello et al., 2020 \\
\hline & $78.6 \pm 7.4 /-$ & $9 /-$ & $\begin{array}{l}\text { Equine-assisted } \\
\text { therapy }\end{array}$ & 10 weeks/20 sessions & MMSE $\uparrow$ & $\begin{array}{l}\text { Borges de Araujo et al., } \\
2019\end{array}$ \\
\hline & $79.43 \pm 6.06 / 83.4 \pm 7.22$ & $7 / 20$ & $\begin{array}{l}\text { Animal-assisted } \\
\text { therapy }\end{array}$ & 11 weeks/5 sessions & MMSE $\uparrow$ & Kanamori et al., 2001 \\
\hline & $82.1 \pm 6.2 / 78.3 \pm 10.3$ & $12 / 12$ & $\begin{array}{l}\text { Animal-assisted } \\
\text { therapy }\end{array}$ & 8 months/16 sessions & MMSE $\uparrow$ & Bono et al., 2015 \\
\hline \multirow[t]{15}{*}{ Various symptoms } & $59-67$ & $3 /-$ & $\begin{array}{l}\text { Animal-assisted } \\
\text { therapy }\end{array}$ & 12 sessions & Aphasia $\downarrow$ & Macauley, 2006 \\
\hline & 65 or older & $22 / 26$ & $\begin{array}{l}\text { Animal-assisted } \\
\text { therapy }\end{array}$ & 12 weeks/24 sessions & Balance $\uparrow$ & Olsen et al., 2016a \\
\hline & 65 or older & $25 / 26$ & $\begin{array}{l}\text { Animal-assisted } \\
\text { therapy }\end{array}$ & 12 weeks/24 sessions & Quality of Life $\uparrow$ & Olsen et al., 2016b \\
\hline & & & & & Depression $\downarrow$ & \\
\hline & $62.6 \pm 6.5 / 63.7 \pm 6.7$ & $41 / 41$ & Horse-riding therapy & 12 weeks/6 sessions & Stroke recovery $\uparrow$ & $\begin{array}{l}\text { Bunketorp-Käll et al., } \\
2017\end{array}$ \\
\hline & & & & & Balance $\uparrow$ & \\
\hline & & & & & Balance $\uparrow$ & \\
\hline & $81.33 \pm 10.20 / 82.07 \pm 8.65$ & $27 / 27$ & $\begin{array}{l}\text { Animal-assisted } \\
\text { therapy }\end{array}$ & 10 weeks/10 sessions & Agitation $\downarrow$ & Majic et al., 2013 \\
\hline & & & & & Depression $\downarrow$ & \\
\hline & $79 \pm 6 /-$ & $10 /-$ & Animal-assisted activity & 1 week/3 sessions & $\begin{array}{l}\text { Neuropsychiatric } \\
\text { symptom } \downarrow\end{array}$ & Mossello et al., 2011 \\
\hline & & & & & Sadness $\downarrow$ & \\
\hline & & & & & Pleasure $\uparrow$ & \\
\hline & & & & & Alertness $\uparrow$ & \\
\hline & $75.25 \pm 6.06 / 75.1 \pm 5.83$ & $16 / 7$ & $\begin{array}{l}\text { Animal-assisted } \\
\text { therapy }\end{array}$ & 24 weeks/24 sessions & Cognitive function $\uparrow$ & Menna et al., 2016 \\
\hline & & & & & Depression $\downarrow$ & \\
\hline
\end{tabular}




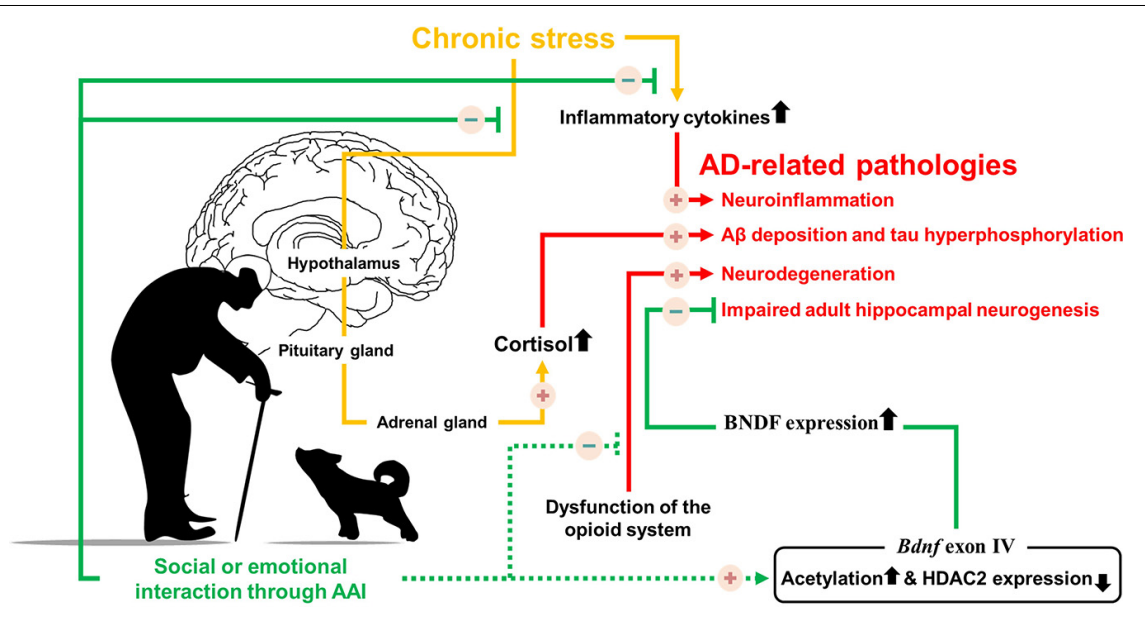

FIGURE 1 | Possible neurological mechanism involved in Alzheimer's disease symptoms alleviation by providing emotional or social interaction through animal assisted intervention. Solid line indicates the known mechanisms, dotted line indicates hypothesized mechanisms.

some symptoms of these disorders can be partially elucidated by impaired AHN (Toda et al., 2019). In addition, many studies have indicated that $\mathrm{AHN}$ is significantly reduced in patients with AD (Moreno-Jimenez et al., 2019) and various mouse models with AD (Rodriguez et al., 2008; Faure et al., 2011; Moon et al., 2014; Wirths, 2017). Social stress, such as decreased emotional or social interactions, is associated with AHN impairment. A study investigating the effects of decreased emotional or social interactions on neurogenesis in young marmosets using BrdU, a cell proliferation marker, reported that social deprivation has induced stress and reduced hippocampal neurogenesis (Cinini et al., 2014). In addition, many studies using mouse models with $\mathrm{AD}$ have reported that decreased emotional or social interactions exacerbate $\mathrm{AD}$-related pathologies and cognitive impairment (Pietropaolo et al., 2009; Huang et al., 2011, 2015); however, the application of social interactions in an mouse model with AD decreased histone deacetylase 2 (HDAC2) expression and occupancy of HDAC2 in the promoter region of brain-derived neurotrophic factor (BDNF) exon IV, resulting in upregulated BDNF expression in the hippocampus region through increased acetylation of $\mathrm{H} 3 \mathrm{~K} 9$ and $\mathrm{H} 4 \mathrm{~K} 12$ histones. Increased BDNF expression improves $\mathrm{AHN}$, synaptic density, and cognition (Hsiao et al., 2014, 2018). These results suggest that increased emotional or social interaction through AAI might involve epigenetic mechanisms and can contribute to cognitive improvement by suppressing the impairment of AHN in patients with AD. Unfortunately, there is no direct evidence of influence of AAI on epigenetic regulation. Therefore, further studies are needed on the epigenetic mechanisms of emotional or social interaction through AAI in patients with $\mathrm{AD}$.

\section{DISCUSSION}

The physiological changes that accompany psychological distress and social isolation decrease state of health of a person, accelerate the development and progression of chronic diseases, and increase mortality (McEwen, 1998). Surprisingly, positive interactions involving companion animals have been found to affect the psychosocial status and reduce psychosocial distress and stress responses. In particular, interactions with animals seem to reduce psychosocial distress by making people appear kinder in a variety of situations (Friedmann and Lockwood, 1991; Rossbach and Wilson, 1992). Interestingly, situations with animals are perceived as more familiar, comfortable, reciprocal, valuable, safe, and happy than situations without animals. In particular, AAI, which is an intervention that uses animals to treat various diseases, has a beneficial effect on psychological and emotional symptoms (Churchill et al., 1999; White et al., 2020). Unfortunately, although various factors, such as the AAI method, applied animal, frequency of AAI, and subject of AAI, are important when evaluating the effectiveness of AAI, these factors differ from study to study. These variables make it difficult to integrate and standardize studies on AAI. Despite these barriers, animals are widely used for the emotional and psychological treatment of various patients (Sable, 1995; Friedmann and Son, 2009; Amerine and Hubbard, 2016). Therefore, this review outlined the neurological mechanisms of AAI, which are putatively focused on the familiar interactions between animals and humans, especially emotional and social interactions, regardless of the animal type used in AAI.

Animal-assisted intervention has therapeutic effects in a variety of health areas. AAI has a beneficial effect on behavioral areas through interaction with animals and the elderly, such as seeing, talking, and touching animals as well as interactions with elderly people talking about animals (Nordgren and Engstrom, 2014). In addition, taking care of animals promotes a sense of motivation for performance in the work and increases self-esteem in older adults, thus showing positive effects in psychosocial areas (Menna et al., 2016). In physical areas, AAI provides improvement of muscle strength and a sense of balance (Grubbs et al., 2016). Furthermore, AAI relaxes the cardiovascular stress response in the elderly (Robinson et al., 2015). In AD, AAI is known to be effective in not only relieving emotional stability and 
depression through love-bonding between animals and patients with $\mathrm{AD}$ but also increasing physical exercise and promoting motivation through walking with and touching animals (Tribet et al., 2008; Klimova et al., 2019). In addition, sundowning, which is one of the symptoms in $\mathrm{AD}$, is also reduced by relieving anxiety through AAI (Churchill et al., 1999). Surprisingly, animals can estimate the risk of patients with $\mathrm{AD}$, and they can prevent them from the risks faced by patients with $A D$ through barking or non-verbal behavior. Unfortunately, in the case of AAI, the patients and animals participating need special care to prevent animal infectious diseases, irritability, and injuries during visits (Jofre, 2005). In particular, AAI should always be performed according to the recommended guidelines of a structured program, trying to prevent infection with animal-related diseases, and applying appropriate interaction models for disease treatment. Interestingly, in a study of risk analysis for the health of people who interact with animals, it was observed that interactions with animals under controlled environmental conditions are beneficial to their health (Brodie et al., 2002; DiSalvo et al., 2006). It is important that the application of AAI be carried out in a controlled environment. Furthermore, an AAI program should be developed through the interaction of various AAI specialists, such as physical therapists, neurologists, psychiatrists, veterinary public health professionals, psychologists, and occupational therapists, and carried out in accordance with the recommended guidelines (Cevizci et al., 2013). An AAI program, created and carried out through a multidisciplinary approach of various specialists, is a professional approach with a clear therapeutic effect among various nonpharmacological interventions.

The multi-targeting character of non-pharmacological interventions is attracting attention as a novel and innovative treatment strategy that exhibits therapeutic effects in various diseases (Olazaran et al., 2010). Unfortunately, the multitargeting characteristic is considered unscientific, as, it is difficult to determine the exact therapeutic effect of the single nonpharmacological intervention. It is also difficult to convert and apply the intervention into a preclinical experimental study, as the understanding of the mechanism of action is insufficient. To overcome disadvantages and to use non-pharmacological intervention for the treatment and prevention of dementia or other neurodegenerative diseases, scientific evidencebased studies, such as reviews of neurological and molecular mechanisms and preclinical experimental studies, are necessary. Similarly, even in the case of AAI, preclinical experimental study

\section{REFERENCES}

Ali, A., Khalil, M., Elariny, H., and Abu-Elfotuh, K. (2017). Study on social isolation as a risk factor in development of Alzheimer's disease in rats. Brain Disord. Ther. $6: 2$.

Amerine, J. L., and Hubbard, G. B. (2016). Using animal-assisted therapy to enrich psychotherapy. Adv. Mind Body Med. 30, 11-11.

Anderson, R. M., Hadjichrysanthou, C., Evans, S., and Wong, M. M. (2017). Why do so many clinical trials of therapies for Alzheimer's disease fail? Lancet 390, 2327-2329. doi: 10.1016/s0140-6736(17)32399-1

Aoki, J., Iwahashi, K., Ishigooka, J., Fukamauchi, F., Numajiri, M., Ohtani, N., et al. (2012). Evaluation of cerebral activity in the prefrontal cortex in mood methods are required to explain the molecular and neurological mechanisms for various effects because it remains difficult for experimental animals to establish the concept of animals from the standpoint of companion animals or experimental animals. In addition, many studies that have applied AAI to patients with $\mathrm{AD}$ have only investigated the ability to improve $\mathrm{AD}$ related symptoms, such as cognitive dysfunction, depression, anxiety, motivation, and exercise. Because studies confirming neurological/pathologic changes, including changes in the inflammatory cytokines, $A \beta$, tau level, and neural circuits in the central nervous system, are insufficient, it is difficult to show the mechanisms by which AAI alleviates AD-related pathologies; however, in this review, we highlighted the value of AAI as a nonpharmacological intervention through the hypothesis that AAI may also affect $\mathrm{AD}$-related pathologies and presented insights for future studies.

The positive-constructive bond resulting from human-animal interactions is the key point for initiating the beneficial effects of AAI. These effects are known to regulate stress, hormone imbalances, cognitive dysfunction, and various symptoms (Table 1). Despite the lack of evidence that AAI can alleviate AD-related pathologies, we hypothesized that emotional or social interactions through AAI could rescue cognitive impairment by alleviating AD-related pathologies. Therefore, based on the accumulated evidence, we speculated on the neurological mechanisms by which AAI affects AD-related pathologies, such as $\mathrm{A} \beta$ deposition, tau hyperphosphorylation, neuroinflammation, and impaired AHN (Figure 1). This review confirms the value of AAI as a non-pharmacological intervention through the hypothesis that AAI used for symptomatic relief of $\mathrm{AD}$ may also affect $\mathrm{AD}$-related pathologies and suggests insights for future research.

\section{AUTHOR CONTRIBUTIONS}

SK, YN, M-JH, CP, MM, and D-HY wrote this review article. All authors contributed to the article and approved the submitted version.

\section{FUNDING}

This work was supported by the Konyang University Research Fund in 2020.

[affective] disorders during animal-assisted therapy (AAT) by near-infrared spectroscopy (NIRS): a pilot study. Int. J. Psychiatry Clin. Pract. 16, 205-213. doi: 10.3109/13651501.2011.644565

Arvanitakis, Z., Shah, R. C., and Bennett, D. A. (2019). Diagnosis and management of dementia: review. JAMA 322, 1589-1599.

Audet, M. C., Mcquaid, R. J., Merali, Z., and Anisman, H. (2014). Cytokine variations and mood disorders: influence of social stressors and social support. Front. Neurosci. 8:416. doi: 10.3389/fnins.2014.00416

Barker, S. B., and Wolen, A. R. (2008). The benefits of human-companion animal interaction: a review. J. Vet. Med. Educ. 35, 487-495. doi: 10.3138/jvme.35.4.487

Barr, C. S., Schwandt, M. L., Lindell, S. G., Higley, J. D., Maestripieri, D., Goldman, D., et al. (2008). Variation at the mu-opioid receptor gene (OPRM1) influences 
attachment behavior in infant primates. Proc. Natl. Acad. Sci. U.S.A. 105, 5277-5281. doi: 10.1073/pnas.0710225105

Bono, A. V., Benvenut, C., Buzzi, M., Ciatti, R., Chiarelli, V., Chiambretto, P., et al. (2015). Effects of animal assisted therapy (AAT) carried out with dogs on the evolution of mild cognitive impairment. G. Gerontol. 63, 32-36.

Borges de Araujo, T., Martins, W. R., Freitas, M. P., Camargos, E., Mota, J., and Safons, M. P. (2019). An exploration of equine-assisted therapy to improve balance, functional capacity, and cognition in older adults with alzheimer disease. J Geriatr. Phys. Ther. 42, E155-E160.

Branson, S., Boss, L., Hamlin, S., and Padhye, N. S. (2020). Animal-assisted activity in critically ill older adults: a randomized pilot and feasibility trial. Biol. Res. Nurs. 22, 412-417. doi: 10.1177/1099800420920719

Brodie, S. J., Biley, F. C., and Shewring, M. (2002). An exploration of the potential risks associated with using pet therapy in healthcare settings. J. Clin. Nurs. 11, 444-456. doi: 10.1046/j.1365-2702.2002.00628.x

Bunketorp-Käll, L., Lundgren-Nilsson, A., Samuelsson, H., Pekny, T., Blomve, K., Pekna, M., et al. (2017). Long-term improvements after multimodal rehabilitation in late phase after stroke: a randomized controlled trial. Stroke 48, 1916-1924. doi: 10.1161/strokeaha.116.016433

Cevizci, S., Murat Sen, H., GüNesş, F., and Karaahmet, E. (2013). “Animal assisted therapy and activities in alzheimer's disease," in Understanding Alzheimer's Disease, ed. I. Zerr (London: IntechOpen).

Charry-Sánchez, J. D., Pradilla, I., and Talero-Gutiérrez, C. (2018). Effectiveness of animal-assisted therapy in the pediatric population: systematic review and meta-analysis of controlled studies. J. Dev. Behav. Pediatr. 39, 580-590. doi: $10.1097 / \mathrm{dbp} .0000000000000594$

Churchill, M., Safaoui, J., Mccabe, B. W., and Baun, M. M. (1999). Using a therapy dog to alleviate the agitation and desocialization of people with Alzheimer's disease. J. Psychosoc. Nurs. Ment. Health Serv. 37, 16-22. doi: 10.3928/02793695-19990401-12

Cinini, S. M., Barnabe, G. F., Galvao-Coelho, N., De Medeiros, M. A., PerezMendes, P., Sousa, M. B., et al. (2014). Social isolation disrupts hippocampal neurogenesis in young non-human primates. Front. Neurosci. 8:45. doi: 10. 3389/fnins.2014.00045

Colonnello, V., Petrocchi, N., Farinelli, M., and Ottaviani, C. (2017). Positive social interactions in a lifespan perspective with a focus on opioidergic and oxytocinergic systems: implications for neuroprotection. Curr. Neuropharmacol. 15, 543-561. doi: 10.2174/1570159x14666160816120209

Copeland, W. E., Sun, H., Costello, E. J., Angold, A., Heilig, M. A., and Barr, C. S. (2011). Child mu-opioid receptor gene variant influences parentchild relations. Neuropsychopharmacology 36, 1165-1170. doi: 10.1038/npp.20 10.251

Coussons-Read, M. E., Okun, M. L., and Nettles, C. D. (2007). Psychosocial stress increases inflammatory markers and alters cytokine production across pregnancy. Brain Behav. Immun. 21, 343-350. doi: 10.1016/j.bbi.2006.08.006

Cummings, J., Lee, G., Ritter, A., Sabbagh, M., and Zhong, K. (2020). Alzheimer's disease drug development pipeline: 2020. Alzheimers Dement. 6:e12050.

DiSalvo, H., Haiduven, D., Johnson, N., Reyes, V. V., Hench, C. P., Shaw, R., et al. (2006). Who let the dogs out? Infection control did: utility of dogs in health care settings and infection control aspects. Am. J. Infect. Control 34, 301-307. doi: 10.1016/j.ajic.2005.06.005

Donovan, N. J., Okereke, O. I., Vannini, P., Amariglio, R. E., Rentz, D. M., Marshall, G. A., et al. (2016). Association of higher cortical amyloid burden with loneliness in cognitively normal older adults. JAMA Psychiatry 73, 1230-1237. doi: 10.1001/jamapsychiatry.2016.2657

Faure, A., Verret, L., Bozon, B., El Tannir El Tayara, N., Ly, M., Kober, F., et al. (2011). Impaired neurogenesis, neuronal loss, and brain functional deficits in the APPxPS1-Ki mouse model of Alzheimer's disease. Neurobiol. Aging 32, 407-418. doi: 10.1016/j.neurobiolaging.2009.03.009

Friedmann, E., and Lockwood, R. (1991). Validation and use of the Animal Thematic Apperception Test (ATAT). Anthrozoös 4, 174-183. doi: 10.2752/ 089279391787057134

Friedmann, E., and Son, H. (2009). The human-companion animal bond: how humans benefit. Vet. Clin. North Am. Small Anim. Pract. 39, 293-326. doi: 10.1016/j.cvsm.2008.10.015

Germain, S. M., Wilkie, K. D., Milbourne, V. M. K., and Theule, J. (2018). Animalassisted psychotherapy and trauma: a meta-analysis. Anthrozoös 31, 141-164. doi: $10.1080 / 08927936.2018 .1434044$
Gocheva, V., Hund-Georgiadis, M., and Hediger, K. (2018). Effects of animalassisted therapy on concentration and attention span in patients with acquired brain injury: a randomized controlled trial. Neuropsychology 32, 54-64. doi: $10.1037 /$ neu0000398

Gong, W., and Ren, Q. (2016). Citalopram attenuates tau hyperphosphorylation of cortex and memory deficits in social isolation-reared rats. Chin. J. Behav. Med. Brain Sci. 25, 193-197.

González-Ramírez, M. T., Ortiz-Jiménez, X. A., and Landero-Hernández, R. (2013). Cognitive-behavioral therapy and animal-assisted therapy: stress management for adults. Altern. Complementary Ther. 19, 270-275. doi: 10. 1089/act.2013.19505

Green, K. N., Billings, L. M., Roozendaal, B., Mcgaugh, J. L., and Laferla, F. M. (2006). Glucocorticoids increase amyloid-beta and tau pathology in a mouse model of Alzheimer's disease. J. Neurosci. 26, 9047-9056. doi: 10.1523/ jneurosci.2797-06.2006

Grubbs, B., Artese, A., Schmitt, K., Cormier, E., and Panton, L. (2016). A pilot study to assess the feasibility of group exercise and animal-assisted therapy in older adults. J. Aging Phys. Act. 24, 322-331. doi: 10.1123/japa.2015-0107

Haggerty, J. M., and Mueller, M. K. (2017). Animal-assisted stress reduction programs in higher education. Innov. High. Educ. 42, 379-389. doi: 10.1007/ s10755-017-9392-0

Handlin, L., Hydbring-Sandberg, E., Nilsson, A., Ejdebäck, M., Jansson, A., and Uvnäs-Moberg, K. (2011). Short-term interaction between dogs and their owners: effects on oxytocin, cortisol, insulin and heart rate-an exploratory study. Anthrozoös 24, 301-315. doi: 10.2752/175303711x13045914865385

Hediger, K., Wagner, J., Künzi, P., Haefeli, A., Theis, F., Grob, C., et al. (2021). Effectiveness of animal-assisted interventions for children and adults with posttraumatic stress disorder symptoms: a systematic review and meta-analysis. Eur. J. Psychotraumatol. 12:1879713. doi: 10.1080/20008198.2021.1879713

Heneka, M. T., Carson, M. J., El Khoury, J., Landreth, G. E., Brosseron, F., Feinstein, D. L., et al. (2015). Neuroinflammation in Alzheimer's disease. Lancet Neurol. 14, 388-405.

Hsiao, Y. H., Chang, C. H., and Gean, P. W. (2018). Impact of social relationships on Alzheimer's memory impairment: mechanistic studies. J. Biomed. Sci. 25:3.

Hsiao, Y. H., Hung, H. C., Chen, S. H., and Gean, P. W. (2014). Social interaction rescues memory deficit in an animal model of Alzheimer's disease by increasing BDNF-dependent hippocampal neurogenesis. J. Neurosci. 34, 16207-16219. doi: 10.1523/jneurosci.0747-14.2014

Hsiao, Y. H., Kuo, J. R., Chen, S. H., and Gean, P. W. (2012). Amelioration of social isolation-triggered onset of early Alzheimer's disease-related cognitive deficit by $\mathrm{N}$-acetylcysteine in a transgenic mouse model. Neurobiol. Dis. 45, 1111-1120. doi: 10.1016/j.nbd.2011.12.031

Hu, M., Zhang, P., Leng, M., Li, C., and Chen, L. (2018). Animal-assisted intervention for individuals with cognitive impairment: a meta-analysis of randomized controlled trials and quasi-randomized controlled trials. Psychiatry Res. 260, 418-427. doi: 10.1016/j.psychres.2017.12.016

Huang, H. J., Liang, K. C., Ke, H. C., Chang, Y. Y., and Hsieh-Li, H. M. (2011). Long-term social isolation exacerbates the impairment of spatial working memory in APP/PS1 transgenic mice. Brain Res. 1371, 150-160. doi: 10.1016/j. brainres.2010.11.043

Huang, H., Wang, L., Cao, M., Marshall, C., Gao, J., Xiao, N., et al. (2015). Isolation housing exacerbates alzheimer's disease-like pathophysiology in aged APP/PS1 mice. Int. J. Neuropsychopharmacol. 18:yu116.

Jofre, M. L. (2005). [Animal- assisted therapy in health care facilities]. Rev. Chilena Infectol. 22, 257-263.

Kamioka, H., Okada, S., Tsutani, K., Park, H., Okuizumi, H., Handa, S., et al. (2014). Effectiveness of animal-assisted therapy: a systematic review of randomized controlled trials. Complement Ther. Med. 22, 371-390.

Kanamori, M., Suzuki, M., Yamamoto, K., Kanda, M., Matsui, Y., Kojima, E., et al. (2001). A day care program and evaluation of animal-assisted therapy (AAT) for the elderly with senile dementia. Am. J. Alzheimers Dis. Other Demen. 16, 234-239. doi: 10.1177/153331750101600409

Kempuraj, D., Thangavel, R., Natteru, P. A., Selvakumar, G. P., Saeed, D., Zahoor, H., et al. (2016). Neuroinflammation induces neurodegeneration. J. Neurol. Neurosurg. Spine 1:1003.

Klimova, B., Toman, J., and Kuca, K. (2019). Effectiveness of the dog therapy for patients with dementia - a systematic review. BMC Psychiatry 19:276. doi: $10.1186 / \mathrm{s} 12888-019-2245-\mathrm{x}$ 
Laun, L. (2003). Benefits of pet therapy in dementia. Home Healthc. Nurse 21, 49-52. doi: 10.1097/00004045-200301000-00011

Leigh-Hunt, N., Bagguley, D., Bash, K., Turner, V., Turnbull, S., Valtorta, N., et al. (2017). An overview of systematic reviews on the public health consequences of social isolation and loneliness. Public Health 152, 157-171. doi: 10.1016/j.puhe. 2017.07.035

Macauley, B. L. (2006). Animal-assisted therapy for persons with aphasia: a pilot study. J. Rehabil. Res. Dev. 43, 357-366. doi: 10.1682/jrrd.2005.01.0027

Majic, T., Gutzmann, H., Heinz, A., Lang, U. E., and Rapp, M. A. (2013). Animalassisted therapy and agitation and depression in nursing home residents with dementia: a matched case-control trial. Am. J. Geriatr. Psychiatry 21, 1052-1059. doi: 10.1016/j.jagp.2013.03.004

Mandrekar-Colucci, S., and Landreth, G. E. (2010). Microglia and inflammation in Alzheimer's disease. CNS Neurol. Disord. Drug Targets 9, 156-167.

McEwen, B. S. (1998). Stress, adaptation, and disease. allostasis and allostatic load. Ann. N.Y. Acad. Sci. 840, 33-44. doi: 10.1111/j.1749-6632.1998.tb09546.x

Menna, L. F., Santaniello, A., Gerardi, F., Di Maggio, A., and Milan, G. (2016). Evaluation of the efficacy of animal-assisted therapy based on the reality orientation therapy protocol in Alzheimer's disease patients: a pilot study. Psychogeriatrics 16, 240-246. doi: 10.1111/psyg. 12145

Ming, G. L., and Song, H. (2011). Adult neurogenesis in the mammalian brain: significant answers and significant questions. Neuron 70, 687-702. doi: 10 . 1016/j.neuron.2011.05.001

Moon, M., Cha, M. Y., and Mook-Jung, I. (2014). Impaired hippocampal neurogenesis and its enhancement with ghrelin in 5XFAD mice. J. Alzheimers Dis. 41, 233-241. doi: 10.3233/jad-132417

Moreno-Jimenez, E. P., Flor-Garcia, M., Terreros-Roncal, J., Rabano, A., Cafini, F., Pallas-Bazarra, N., et al. (2019). Adult hippocampal neurogenesis is abundant in neurologically healthy subjects and drops sharply in patients with Alzheimer's disease. Nat. Med. 25, 554-560. doi: 10.1038/s41591-019-0375-9

Mossello, E., Ridolfi, A., Mello, A. M., Lorenzini, G., Mugnai, F., Piccini, C., et al. (2011). Animal-assisted activity and emotional status of patients with Alzheimer's disease in day care. Int. Psychogeriatr. 23, 899-905. doi: 10.1017/ s1041610211000226

Mu, Y., and Gage, F. H. (2011). Adult hippocampal neurogenesis and its role in Alzheimer's disease. Mol. Neurodegener. 6:85. doi: 10.1186/1750-1326-6-85

Nordgren, L., and Engstrom, G. (2014). Effects of dog-assisted intervention on behavioural and psychological symptoms of dementia. Nurs. Older People 26, 31-38. doi: 10.7748/nop2014.03.26.3.31.e517

Olazaran, J., Reisberg, B., Clare, L., Cruz, I., Pena-Casanova, J., Del Ser, T., et al. (2010). Nonpharmacological therapies in Alzheimer's disease: a systematic review of efficacy. Dement. Geriatr. Cogn. Disord. 30, 161-178.

Olsen, C., Pedersen, I., Bergland, A., Enders-Slegers, M. J., and Ihlebaek, C. (2016a). Effect of animal-assisted activity on balance and quality of life in home-dwelling persons with dementia. Geriatr. Nurs. 37, 284-291. doi: 10.1016/j.gerinurse. 2016.04.002

Olsen, C., Pedersen, I., Bergland, A., Enders-Slegers, M. J., Patil, G., and Ihlebaek, C. (2016b). Effect of animal-assisted interventions on depression, agitation and quality of life in nursing home residents suffering from cognitive impairment or dementia: a cluster randomized controlled trial. Int. J. Geriatr. Psychiatry 31, 1312-1321. doi: 10.1002/gps.4436

Ouanes, S., and Popp, J. (2019). High cortisol and the risk of dementia and alzheimer's disease: a review of the literature. Front. Aging Neurosci. 11:43. doi: $10.3389 /$ fnagi.2019.00043

Park, J. Y., Ko, H. J., Kim, A. S., Moon, H. N., Choi, H. I., Kim, J. H., et al. (2019). Effects of pet insects on cognitive function among the elderly: an fMRI study. J. Clin. Med. 8:1705. doi: 10.3390/jcm8101705

Park, S., Bak, A., Kim, S., Nam, Y., Kim, H. S., Yoo, D. H., et al. (2020). Animal-assisted and pet-robot interventions for ameliorating behavioral and psychological symptoms of dementia: a systematic review and meta-analysis. Biomedicines 8:150. doi: 10.3390/biomedicines 8060150

Pendry, P., and Vandagriff, J. L. (2019). Animal visitation program (AVP) reduces cortisol levels of university students: a randomized controlled trial. AERA Open 5:2332858419852592.

Pietropaolo, S., Sun, Y., Li, R., Brana, C., Feldon, J., and Yee, B. K. (2009). Limited impact of social isolation on Alzheimer-like symptoms in a triple transgenic mouse model. Behav. Neurosci. 123, 181-195. doi: 10.1037/a001 3607
Popp, J., Wolfsgruber, S., Heuser, I., Peters, O., Hull, M., Schroder, J., et al. (2015). Cerebrospinal fluid cortisol and clinical disease progression in MCI and dementia of Alzheimer's type. Neurobiol. Aging 36, 601-607. doi: 10.1016/j. neurobiolaging.2014.10.031

Querfurth, H. W., and LaFerla, F. M. (2010). Alzheimer's disease. N. Engl. J. Med. $362,329-344$.

Ren, Q. G., Gong, W. G., Wang, Y. J., Zhou, Q. D., and Zhang, Z. J. (2015). Citalopram attenuates tau hyperphosphorylation and spatial memory deficit induced by social isolation rearing in middle-aged rats. J. Mol. Neurosci. 56, 145-153. doi: 10.1007/s12031-014-0475-4

Ricci, S., Fuso, A., Ippoliti, F., and Businaro, R. (2012). Stress-induced cytokines and neuronal dysfunction in Alzheimer's disease. J. Alzheimers Dis. 28, 11-24. doi: 10.3233/jad-2011-110821

Robinson, H., Macdonald, B., and Broadbent, E. (2015). Physiological effects of a companion robot on blood pressure of older people in residential care facility: a pilot study. Australas. J. Ageing 34, 27-32. doi: 10.1111/ajag.12099

Rodriguez, J. J., Jones, V. C., Tabuchi, M., Allan, S. M., Knight, E. M., Laferla, F. M., et al. (2008). Impaired adult neurogenesis in the dentate gyrus of a triple transgenic mouse model of Alzheimer's disease. PLoS One 3:e2935. doi: 10.1371/journal.pone.0002935

Rossbach, K. A., and Wilson, J. P. (1992). Does a dog's presence make a person appear more likable: Two studies. Anthrozoös 5, 40-51. doi: 10.2752/ 089279392787011593

Sable, P. (1995). Pets, attachment, and well-being across the life cycle. Soc. Work $40,334-341$.

Santaniello, A., Garzillo, S., Amato, A., Sansone, M., Di Palma, A., Di Maggio, A., et al. (2020). Animal-assisted therapy as a non-pharmacological approach in alzheimer's disease: a retrospective study. Animals 10:1142. doi: 10.3390/ ani10071142

Slavich, G. M., Way, B. M., Eisenberger, N. I., and Taylor, S. E. (2010). Neural sensitivity to social rejection is associated with inflammatory responses to social stress. Proc. Natl. Acad. Sci. U.S.A. 107, 14817-14822. doi: 10.1073/pnas. 1009164107

Sockalingam, S., Li, M., Krishnadev, U., Hanson, K., Balaban, K., Pacione, L. R., et al. (2008). Use of animal-assisted therapy in the rehabilitation of an assault victim with a concurrent mood disorder. Issues Ment. Health Nurs. 29, 73-84. doi: 10.1080/01612840701748847

Souter, M. A., and Miller, M. D. (2007). Do animal-assisted activities effectively treat depression? A Meta-Analysis. Anthrozoös 20, 167-180. doi: 10.2752/ $175303707 \times 207954$

Stapleton, M. (2016). Effectiveness of animal assisted therapy after brain injury: a bridge to improved outcomes in CRT. NeuroRehabilitation 39, 135-140. doi: $10.3233 /$ nre- 161345

Straub, R. O. (2011). Health Psychology. Basingstoke: Macmillan.

Sun, B., Halabisky, B., Zhou, Y., Palop, J. J., Yu, G., Mucke, L., et al. (2009). Imbalance between GABAergic and glutamatergic transmission impairs adult neurogenesis in an animal model of alzheimer's disease. Cell Stem Cell 5, 624-633. doi: 10.1016/j.stem.2009.10.003

Tai, L. M., Ghura, S., Koster, K. P., Liakaite, V., Maienschein-Cline, M., Kanabar, P., et al. (2015). APOE-modulated abeta-induced neuroinflammation in Alzheimer's disease: current landscape, novel data, and future perspective. J. Neurochem. 133, 465-488. doi: 10.1111/jnc.13072

Terada, T., Yokokura, M., Obi, T., Bunai, T., Yoshikawa, E., Ando, I., et al. (2019). In vivo direct relation of tau pathology with neuroinflammation in early Alzheimer's disease. J. Neurol. 266, 2186-2196. doi: 10.1007/s00415-01909400-2

Toda, T., Parylak, S. L., Linker, S. B., and Gage, F. H. (2019). The role of adult hippocampal neurogenesis in brain health and disease. Mol. Psychiatry 24, 67-87. doi: 10.1038/s41380-018-0036-2

Trezza, V., Damsteegt, R., Achterberg, E. J., and Vanderschuren, L. J. (2011). Nucleus accumbens mu-opioid receptors mediate social reward. J. Neurosci. 31, 6362-6370. doi: 10.1523/jneurosci.5492-10.2011

Tribet, J., Boucharlat, M., and Myslinski, M. (2008). [Animal-assisted therapy for people suffering from severe dementia]. Encephale 34, 183-186.

Uchino, B. N., Trettevik, R., Kent De Grey, R. G., Cronan, S., Hogan, J., and Baucom, B. R. W. (2018). Social support, social integration, and inflammatory cytokines: a meta-analysis. Health Psychol. 37, 462-471. doi: 10.1037/ hea0000594 
Virués-Ortega, J., Pastor-Barriuso, R., Castellote, J. M., Población, A., and De Pedro-Cuesta, J. (2012). Effect of animal-assisted therapy on the psychological and functional status of elderly populations and patients with psychiatric disorders: a meta-analysis. Health Psychol. Rev. 6, 197-221. doi: 10.1080/ 17437199.2010.534965

White, E., Zippel, J., and Kumar, S. (2020). The effect of equine-assisted therapies on behavioural, psychological and physical symptoms for children with attention deficit/hyperactivity disorder: a systematic review. Complement Ther. Clin. Pract. 39:101101. doi: 10.1016/j.ctcp.2020.1 0110

Wilson, R. S., Krueger, K. R., Arnold, S. E., Schneider, J. A., Kelly, J. F., Barnes, L. L., et al. (2007). Loneliness and risk of Alzheimer disease. Arch. Gen. Psychiatry 64, 234-240.

Wirths, O. (2017). Altered neurogenesis in mouse models of Alzheimer disease. Neurogenesis 4:e1327002. doi: 10.1080/23262133.2017.1327002

World Health Organization [WHO] (2020). Dementia. Geneva: World Health Organization.
Zhang, Y., Yan, F., Li, S., Wang, Y., and Ma, Y. (2021). Effectiveness of animalassisted therapy on pain in children: a systematic review and meta-analysis. Int. J. Nurs. Sci. 8, 30-37. doi: 10.1016/j.ijnss.2020.12.009

Zheng, J., Li, H. L., Tian, N., Liu, F., Wang, L., Yin, Y., et al. (2020). Interneuron accumulation of phosphorylated tau impairs adult hippocampal neurogenesis by suppressing GABAergic transmission. Cell Stem Cell 26, 331-345.e6.

Conflict of Interest: The authors declare that the research was conducted in the absence of any commercial or financial relationships that could be construed as a potential conflict of interest.

Copyright (c) $2021 \mathrm{Kim}$, Nam, Ham, Park, Moon and Yoo. This is an open-access article distributed under the terms of the Creative Commons Attribution License (CC BY). The use, distribution or reproduction in other forums is permitted, provided the original author(s) and the copyright owner(s) are credited and that the original publication in this journal is cited, in accordance with accepted academic practice. No use, distribution or reproduction is permitted which does not comply with these terms. 